\title{
BMJ Open Retrospective case-control study to evaluate hypocalcaemia as a distinguishing feature of COVID-19 compared with other infective pneumonias and its association with disease severity
}

\author{
Meera Mehta (D) , ${ }^{1}$ Hakim Ghani (1) , ${ }^{1}$ Felix Chua, ${ }^{2,3}$ Adrian Draper, ${ }^{4}$ \\ Sam Calmonson, ${ }^{1}$ Meghna Prabhakar, ${ }^{1}$ Rijul Shah, ${ }^{1}$ Alessio Navarra, ${ }^{1}$ \\ Tejal Vaghela, ${ }^{1}$ Andrew Barlow, ${ }^{1}$ Rama Vancheeswaran ${ }^{1}$
}

To cite: Mehta M, Ghani $\mathrm{H}$, Chua F, et al. Retrospective case-control study to evaluate hypocalcaemia as a distinguishing feature of COVID-19 compared with other infective pneumonias and its association with disease severity. BMJ Open 2021;11:e053810. doi:10.1136/ bmjopen-2021-053810

- Prepublication history and additional supplemental material for this paper are available online. To view these files, please visit the journal online (http://dx.doi.org/10.1136/ bmjopen-2021-053810)

Received 14 June 2021 Accepted 15 October 2021

Check for updates

(C) Author(s) (or their employer(s)) 2021. Re-use permitted under CC BY-NC. No commercial re-use. See rights and permissions. Published by BMJ.

For numbered affiliations see end of article.

Correspondence to Dr Meera Mehta; meera.mehta2@nhs.net

\section{ABSTRACT}

Objectives To investigate whether calcium derangement was a specific feature of COVID-19 that distinguishes it from other infective pneumonias, and its association with disease severity.

Design A retrospective observational case-control study looking at serum calcium on adult patients with COVID-19, and community-acquired pneumonia (CAP) or viral pneumonia (VP).

Setting A district general hospital on the outskirts of London, UK.

Participants 506 patients with COVID-19, 95 patients with CAP and 152 patients with VP.

Outcome measures Baseline characteristics including hypocalcaemia in patients with COVID-19, CAP and VP were detailed. For patients with COVID-19, the impact of an abnormally low calcium level on the maximum level of hospital care, as a surrogate of COVID-19 severity, was evaluated. The primary outcome of maximal level of care was based on the WHO Clinical Progression Scale for COVID-19.

Results Hypocalcaemia was a specific and common clinical finding in patients with COVID-19 that distinguished it from other respiratory infections. Calcium levels were significantly lower in those with severe disease. Ordinal regression of risk estimates for categorised care levels showed that baseline hypocalcaemia was incrementally associated with $\mathrm{OR}$ of 2.33 (95\% Cl 1.5 to 3.61) for higher level of care, superior to other variables that have previously been shown to predict worse COVID-19 outcome. Serial calcium levels showed improvement by days 7-9 of admission, only in survivors of COVID-19.

Conclusion Hypocalcaemia is specific to COVID-19 and may help distinguish it from other infective pneumonias. Hypocalcaemia may independently predict severe disease and warrants detailed prognostic investigation. The fact that decreased serum calcium is observed at the time of clinical presentation in COVID-19, but not other infective pneumonias, suggests that its early derangement is
Strengths and limitations of this study

- This is the first study to report calcium levels in COVID-19 in comparison to other infective pneumonias, including community-acquired pneumonia and viral pneumonia.

- This is the first study to track calcium levels during admission in survivors and non-survivors of COVID-19.

- This study is limited by its retrospective nature.

- This study is limited by its modest sample size.

- This study is limited by the measurement of albumin-corrected rather than ionised calcium.

pathophysiological and may influence the deleterious evolution of this disease.

Trial registration number 20/HRA/2344.

\section{INTRODUCTION}

COVID-19, the disease responsible for the pandemic caused by the SARS-CoV-2, has resulted in nearly 3 million deaths worldwide. The identification of well-defined COVID-19 prognostic markers has advanced the clinical understanding of this disease. ${ }^{1-3}$ Hypocalcaemia has been reported in the context of acute COVID-19 where it has been associated with an increased risk of hospitalisation and morbidity. ${ }^{4-9}$ However, its role in predicting mortality has been less clear, with reports of a conflicting effect. ${ }^{6} 10-12$

Neither the pathogenic role played by hypocalcaemia in COVID-19 nor the possibility that its occurrence might simply reflect underlying illness severity has been established. Indeed, hypocalcaemia is frequently 
observed in critically ill patients in intensive care settings, but the aetiology of this is unknown. However, the fact that decreased serum calcium has been consistently observed at the time of clinical presentation suggests that its early derangement may potentially influence the deleterious evolution of this disease at an individual level.

Calcium is a versatile intracellular messenger involved in controlling diverse biological processes spanning gene expression, cell proliferation and cell death. ${ }^{13}$ Its role in promoting pathogen apoptosis during intracellular infection has been recognised in host defence. ${ }^{13}$ Conversely, some viruses have evolved ways to promote calcium availability to their own pathogenic, replicative and survival advantage. ${ }^{14-16}$ More specifically, alterations in calcium homeostasis effected by enhanced ion transportation through coronavirus envelope (E) proteins that act as viroporins have been linked to the activation of inflammatory cascades by the SARS- 1 coronavirus. ${ }^{17}$ It has recently been proposed that SARS-CoV-2 may also use this or similar mechanisms to augment its infectivity during host-virus interactions. ${ }^{18}$

In the current retrospective study, we sought to compare the prevalence of hypocalcaemia and its association with clinical outcome in different forms of infective pneumonia including COVID-19.

\section{METHODS}

\section{Design and setting}

This was a retrospective study conducted at Watford General Hospital, West Hertfordshire NHS Trust (a large district general hospital on the outskirts of London, UK).

\section{Inclusion criteria}

Adult patients aged 18 years or older with positive SARSCoV-2 nucleic acid testing by real-time reverse transcription PCR (rRT-PCR) were retrospectively recruited between 1 March and 16 May 2020. More detailed data collection methodology has been published elsewhere. ${ }^{19}$

Control cases diagnosed with community-acquired pneumonia (CAP) and viral pneumonia (VP) were identified through a clinical database for three defined intervals over two preceding winters prior to the emergence of COVID-19 (January to February 2018, January to February 2019 and September to December 2019).

CAP was diagnosed on the basis of respiratory symptoms and signs indicative of a lower respiratory tract infection, with new plain radiographic abnormalities including lobar infiltrates or consolidation. ${ }^{20} \mathrm{VP}$ was diagnosed by positive viral identification in swabbed nasal and oropharyngeal acute respiratory specimens and analysed by the BioFire respiratory panel, which identifies among others influenza $A$ and $B$, rhinovirus/enterovirus, Human metapneumovirus, coronaviruses (OC43, HKU1, NL63), picornovirus and respiratory syncytial virus.

\section{Exclusion criteria}

We excluded patients with chronic kidney disease $(\mathrm{CKD})^{21}$ and those receiving vitamin $\mathrm{D}$ or calcium supplementation. Nine hundred and ninety-four patients were eligible for inclusion into the study. Three hundred and twentyfive patients were excluded due to coexisting CKD or calcium supplementation. One hundred and sixty-three patients did not have calcium measured at presentation. Missing data were handled by listwise case deletion where calcium measurements at presentation were not available, and pairwise deletion where data in variables of interest were not available.

\section{Sample size}

The study size was determined by the incident case load of COVID-19 and non-COVID-19 pneumonia over the prespecified dates.

\section{Outcome measures}

An analysis was first undertaken to highlight differences in core clinical characteristics between patients with COVID-19, CAP and VP. Subsequently and only for the COVID-19 subgroup, the impact of an abnormally low calcium level on the maximum level of hospital care, as a surrogate of COVID-19 severity, was evaluated. The selection of maximal care level as the primary outcome was based on the WHO Clinical Progression Scale for COVID$19 .^{22}$ Patients were categorised at three levels of care: (1) mild ambulatory disease for patients qualifying for monitoring in a virtual hospital (VH) setting, (2) moderate hospitalised disease for individuals managed on a medical ward who intermittently required supplemental oxygen, (3) severe hospitalised disease for patients who received continuous positive airway pressure therapy, and/or who required invasive mechanical ventilation in the intensive care unit (ICU).

\section{Definitions}

Hypocalcaemia was defined as albumin-corrected serum calcium $<2.2 \mathrm{mmol} / \mathrm{L}$ in serum, a level based on studydefined cut-points. An optimal cut-point of $2.195 \mathrm{mmol} / \mathrm{L}$ was associated with a sensitivity of $47 \%$, specificity of $43 \%$ and univariate OR of 1.51 for in-hospital death (95\% CI 1.14 to $2.00 ; \mathrm{p}<0.01)$. Calcium levels were measured at baseline on first presentation to hospital, unless specified otherwise. Blood was collected using standard venepuncture techniques into a serum separating tube and sent to the laboratory for testing. An index of oxygenation was calculated using the oxygen saturation-to-fraction of inspired oxygen (S:F) ratio, determined by dividing the $\mathrm{SpO}_{2}$ by the $\mathrm{FiO}_{2}$. A cut-off of 4.38 represented saturations of $92 \%$ on fraction of inspired oxygen of $21 \%$ (room air).

\section{Subgroup analysis}

A subgroup analysis was undertaken to assess the 25-hydroxyvitamin D level in patients with COVID-19 pneumonia; because vitamin $\mathrm{D}$ was not routinely measured as part of protocolised COVID-19 care, we included the result of a small subgroup of patients with 
Table 1 Baseline characteristics of patients with COVID-19 and non-COVID-19 pneumonia

\begin{tabular}{|c|c|c|c|c|}
\hline & & COVID-19 & CAP & VP \\
\hline Total (N) & & 506 & 95 & 152 \\
\hline Median age (IQR) & & $65(52-80)$ & $79(67-86)$ & $68(45-79)$ \\
\hline Gender $(n ; \%$ of $N)$ & Female & $228(45.0)$ & $44(46.3)$ & 85 (55.9) \\
\hline \multirow[t]{3}{*}{ Ethnicity (n; \% of N) } & White & $383(75.6)$ & $81(85.2)^{*}$ & $134(88.1)^{\star}$ \\
\hline & Black & $30(5.9)$ & $1(1.0)^{*}$ & $0(0)^{*}$ \\
\hline & Other & $10(1.9)$ & $2(2.1)$ & $6(3.9)$ \\
\hline \multirow[t]{2}{*}{ Smoking (n; \% of N) } & Never & $420(83)$ & $75(78.1)$ & Not known \\
\hline & Ever & $86(16.9)$ & $21(21.8)$ & Not known \\
\hline \multirow[t]{2}{*}{ Comorbidities } & Obesity & $148(29.2 \%)$ & $28(29.4 \%)$ & Not known \\
\hline & Autoimmune & $51(10.0 \%)$ & $9(9.4 \%)$ & Not known \\
\hline S:F ratio $<4.38$ & & $191 / 401(47 \%)$ & $40 / 78(51 \%)$ & Not known \\
\hline $\mathrm{RR}>24$ breaths/min & & $235 / 455(51 \%)$ & $47 / 87(54 \%)$ & Not known \\
\hline CRP >50 mg/L & & $304 / 501(60 \%)$ & 63/94 (67\%) & $68 / 151(45 \%)$ \\
\hline WCC $>11 \times 10^{9} / \mathrm{L}$ & & $96 / 505$ (19\%) & $56 / 95(58 \%)^{*}$ & $92 / 151(60 \%)^{*}$ \\
\hline Lymph $<0.7 \times 10^{9} / \mathrm{L}$ & & $251 / 505(55 \%)$ & $56 / 95(58 \%)$ & 48/151 (31\%) \\
\hline eGFR <60 mg/mmol & & 205/436 (31.4\%) & $43 / 95(45.2 \%)$ & $54 / 152(35.5 \%)$ \\
\hline $\mathrm{CXR} \geq 4$ abnormal zones & & $224 / 487$ (45\%) & $5 / 95(5.2 \%)^{*}$ & $4 / 147(2.7 \%)^{*}$ \\
\hline Median LOS (days) & & 7.5 & 5.43 & 4 \\
\hline
\end{tabular}

Baseline characteristics of patients with COVID-19, community-acquired pneumonia (CAP) and viral pneumonia (VP) compared. ${ }^{*} \mathrm{P}<0.05$ versus COVID-19.

CRP, C-reactive protein; CXR, chest X-ray; DM, diabetes mellitus; eGFR, estimated glomerular filtration rate; HTN, hypertension; LOS, length of stay; Lymph, lymphocyte count; RR, respiratory rate; S:F ratio, oxygen saturation-to-fraction of inspired oxygen ratio; WCC, white cell count.

mild or severe COVID-19 (presenting between December 2020 and January 2021) where the measurement was recorded prospectively within 3 days of a positive SARSCoV-2 rRT-PCR test.

\section{Patient and public involvement}

It was not appropriate or possible to involve patients or the public in the design, or conduct, or reporting, or dissemination plans of our research which was conducted during the COVID-19 pandemic.

\section{Statistical analysis}

Continuous variables were presented as median with IQR and the Kruskal-Wallis equality of population or $\mathrm{H}$ test was used to compare differences among groups. Categorical variables were expressed as frequency $(\%)$ and analysed using Pearson's $\chi^{2}$ test or Fisher's exact test. To assess the effect of hypocalcaemia on the primary outcome, and taking account of potential covariate effects with other independent variables, we used ordinal (ordered) logistic regression to compare the ORs of these variables on predefined outcome categories of maximal care level. A goodness-of-fit (Brant) test was employed to ensure that the proportional odds assumption was met. A nonsignificant test statistic $(\mathrm{p}>0.05)$ provided evidence that the full model did not show a significant difference to restricted models with selected explanatory variables. Following this, a partial proportional odds model was refined to test the parallel odds against alternatives. ${ }^{23} \mathrm{~A}$ two-sided $p$ value $<0.05$ was considered statistically significant. All analyses were performed using GraphPad Prism V.9.0.2 and STATA V.16 (Stata, Texas, USA).

\section{RESULTS}

Differences in demographic and clinical characteristics between study subgroups

We analysed data from 506 patients ( $54.9 \%$ male) with COVID19, 95 patients with CAP (53.6\% male) and 152 patients with VP (44\% male). The median age of the COVID-19 cohort was 65 (IQR 52-80), similar to that of patients with VP (68; 


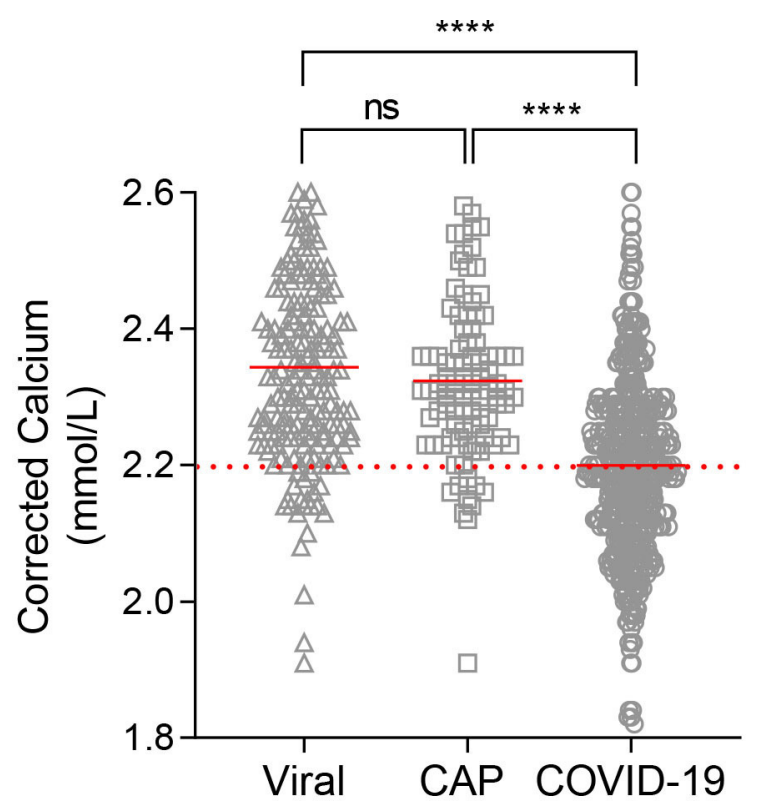

Figure 1 Serum-corrected calcium at presentation in patients with community-acquired pneumonia (CAP), viral pneumonia (VP) and COVID-19. Dashed line represents cutoff point for hypocalcaemia, solid red line represents median. ${ }^{\star * \star *} \mathrm{P}<0.0001$. ns, not significant.

IQR 45-79) but lower than the median age of patients with CAP (79; IQR 67-86) (table 1).

Among patients with COVID-19, individuals of White Caucasian ethnicity constituted $75.6 \% \quad(383 / 506)$ of the cohort while Asian, Black and other minor ethnicities represented $16.5 \%, 4.5 \%$ and $1.7 \%$, respectively. In comparison, White Caucasian ethnicity comprised a higher proportion of patients with CAP $(85.2 \%)$ and VP $(88.1 \%)(\mathrm{p}<0.001$ vs COVID-19).

To assess the level of severity of pneumonic illness across the three cohorts, we used a panel of common clinical variables conventionally taken to indicate disease severity at presentation. We found similar levels of hypoxia, tachypnoea and baseline C-reactive protein (CRP) in patients with COVID-19 and CAP. Whereas CAP was associated with higher peripheral leucocytosis, a significantly higher proportion of patients with COVID-19 had multifocal infiltrates affecting four or more zones on plain chest radiography. Patients with VP had significantly lower CRP and limited radiographic changes.

The median length of hospital stay in patients with COVID-19 was significantly longer compared with CAP and VP: COVID-19 7.5 days (IQR 4.0-13.2), CAP 5.4 days (IQR 2.2-10.5) and VP 4.0 days (IQR 1.1-9.5) ( $<<0.01$ ). The inpatient mortality among patients with COVID-19 was $30.6 \%$, similar to that of patients with CAP (28\%) but significantly higher than patients with VP $(4.6 \%, \mathrm{p}<0.0001$ COVID-19 vs VP) (table 1).

Hypocalcaemia was evident in $53 \%$ of patients with COVID-19 at initial assessment but only in $11.5 \%$ (11/95) and $10.5 \%(16 / 152)$ of patients with CAP and VP, respectively ( $<<0.0001$ vs COVID-19) (figure 1 ). Hypocalcaemic patients with COVID-19 were more likely to be male
(62.1\% vs $46.0 \% ; \mathrm{p}<0.001)$ and obese $(34.0 \%$ vs $23.8 \%$; $\mathrm{p}<0.05)$. Median-corrected calcium in COVID-19 was 2.19 $\mathrm{mmol} / \mathrm{L}$ (IQR 2.11-2.27) compared with $2.31 \mathrm{mmol} / \mathrm{L}$ (IQR 2.24-2.38) in patients with CAP and $2.34 \mathrm{mmol} / \mathrm{L}$ (IQR 2.24-2.44) in those with VP. The between-group difference in baseline serum-adjusted calcium was significant $(\mathrm{p}<0.001)$.

\section{Association of hypocalcaemia with indices of infection severity in COVID-19}

Hypocalcaemia in patients with COVID-19 was associated with greater physiological, biochemical and radiological derangement than normocalcaemia (figure 2). Crucially, patients with hypocalcaemia had a higher median respiratory rate compared with patients with normocalcaemia (24/min, IQR 20-30 vs 22/min, IQR 18-28; p<0.005) and a lower baseline S:F ratio indicative of worse hypoxia at presentation ( 4.38 vs $4.52 ; \mathrm{p}<0.01)$. The extent of baseline radiographic abnormality attributed to COVID-19 pneumonia was similarly greater in those with hypocalcaemia ( $<<0.001$ vs normocalcaemia). Furthermore, hypocalcaemia was associated with a higher CRP (85, IQR 42-148 vs 60, IQR 32-124; $\mathrm{p}<0.01)$. Although peripheral leucocytosis was not associated with hypocalcaemia, patients with low calcium had statistically worse lymphopenia than normocalcaemic individuals even though the difference was small $\left(0.85 \times 10^{9} / \mathrm{L}\right.$ vs $\left.0.98 \times 10^{9} / \mathrm{L} ; \mathrm{p}<0.05\right)$.

Differences in calcium could not be explained by acid base disturbances (online supplemental figure 1A) or by advancing age (online supplemental figure 1B).

\section{Hypocalcaemia as a predictor of higher levels of respiratory care in patients with COVID-19}

Median serum calcium level was lower in those with moderate disease compared with those with mild COVID-19 $(p<0.001)$, and lower still in those with severe disease $(\mathrm{p}<0.0001)$ (figure $3 \mathrm{~A})$.

Hypocalcaemia was more common in patients with COVID-19 segregated by increasing level of hospital care. Whereas $27.8 \%$ (22/79) of patients with mild ambulatory COVID-19 were hypocalcaemic, the rate doubled to 53.3\% (175/328) among those with moderate severity COVID-19. The proportion was higher still $(72.1 \%$; 70/97) in individuals with severe COVID-19 (table 2). Hypocalcaemia at presentation was thus associated with a higher unadjusted OR for severe COVID-19 (2.74; 95\% CI 1.69 to 4.43). As expected, hypocalcaemia was also associated with an increased length of hospital stay compared with patients who had normal corrected calcium (median 7.5 vs 4.0 days; $\mathrm{p}<0.0001$ ) (figure 3B). In contrast, hypocalcaemia in patients with CAP and VP was not associated with either disease severity or length of stay (online supplemental figure 2 and online supplemental table 1).

Evaluation of hypocalcaemia as an independent predictor of a higher level of clinical care, a practical surrogate for requirement for higher respiratory support, was undertaken using ordinal logistic regression. In recognising that COVID-19 pneumonia is associated with 

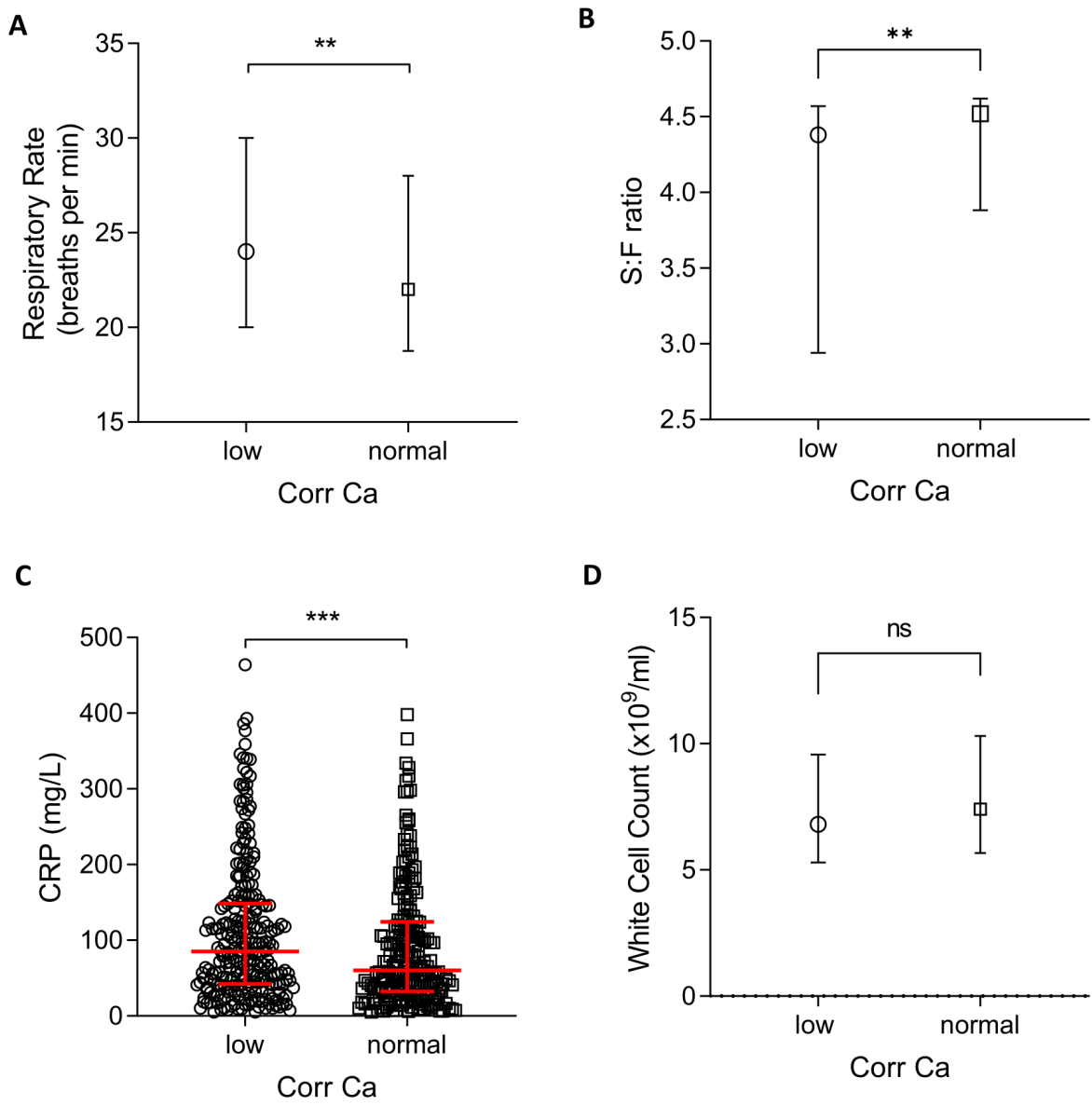

D

$\mathbf{E}$

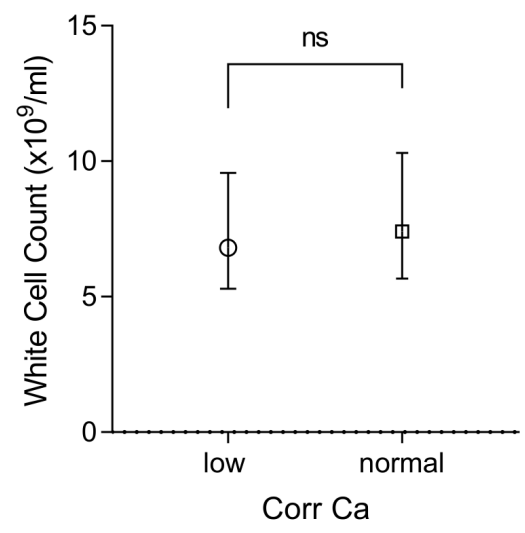

$\mathbf{F}$
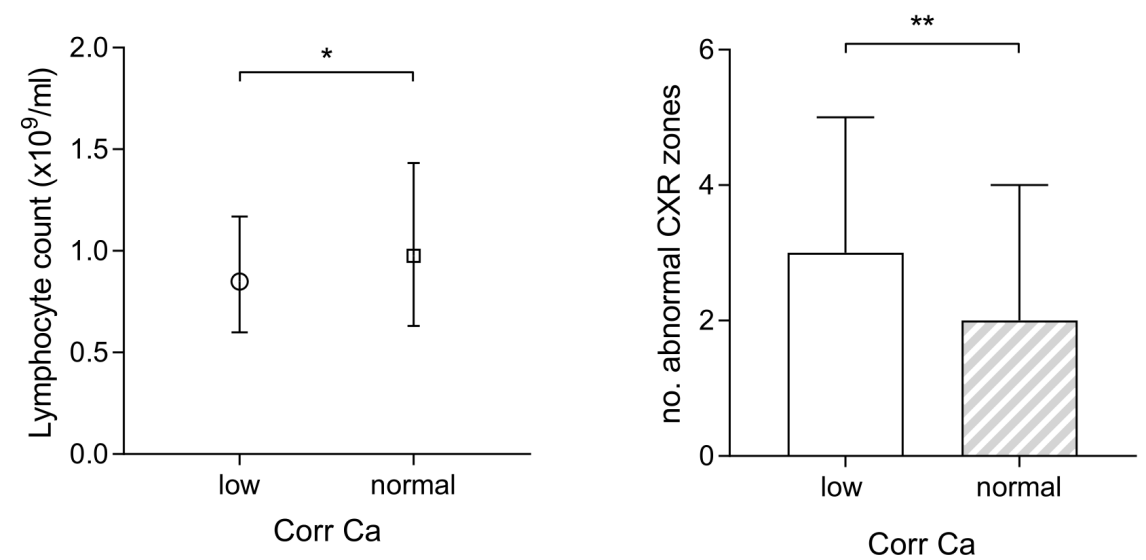

Figure 2 Physiological, biological and radiological severity markers in hypocalcaemic (corrected calcium $<2.2 \mathrm{mmol} / \mathrm{L}$ ) and normocalcaemic ( $\geq 2.2 \mathrm{mmol} / \mathrm{L})$ patients with COVID-19. (A) Respiratory rate. (B) Oxygen saturation-to-fraction of inspired oxygen (S:F) ratio. (C) White cell count. (D) C-reactive protein (CRP). (E) Lymphocyte count. (F) Number of abnormal chest X-ray (CXR) zones. Plots show median and IQR. ${ }^{*} \mathrm{P}<0.05 ;{ }^{* *} \mathrm{p}<0.01 ;{ }^{* \star *} \mathrm{p}<0.001$. ns, not significant.

a wide range of severity and that patients may progress from initially mild to more consequential disease, our analyses made two assumptions: first, that the outcome categories (different care levels) followed a natural order within the studied range of disease severity, and second, proportional odds assumption of the effect of hypocalcaemia on the same outcome categories was obeyed. A goodness-of-fit test, in this case the Brant test, was used to determine proportional odds assumption (online supplemental table 2).
Based on initial analyses, a partial proportional odds model was developed that excluded increasing age as an exploratory variable as it violated the proportional (or parallel) odds assumption rule for the chosen outcome (Peterson and Harrell, 1990). Older age has been shown in numerous studies to be the most dominant independent predictor of death in COVID-19, suggesting that its prognostic impact on any categorised COVID-19 outcome was likely to be disproportionate. An analysis of ordinal logistic regression was thus formulated based 
A

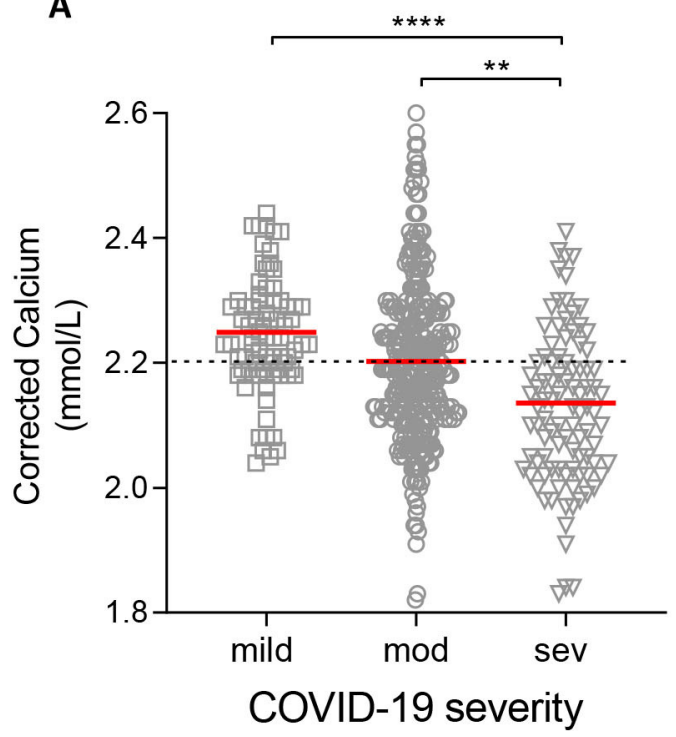

B

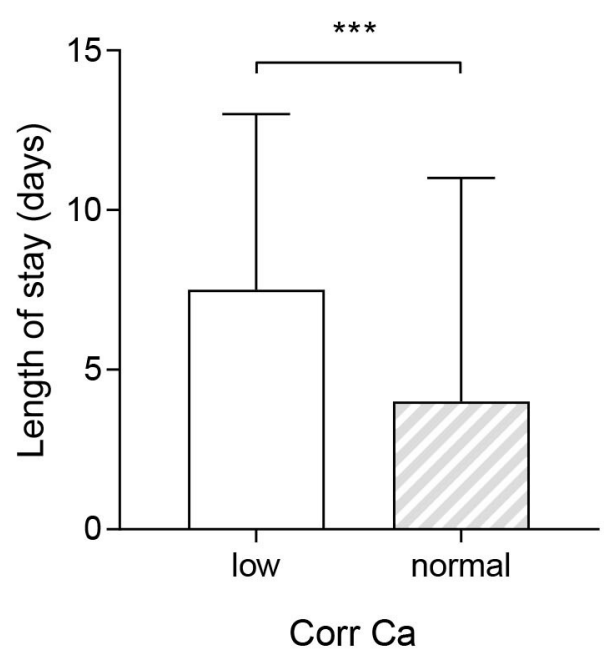

Figure 3 Association of calcium levels in patients with COVID-19 and disease severity or length of stay (LOS). (A) Calcium levels in patients with mild disease (no supplemental oxygen requirement managed in a virtual hospital setting), moderate disease (patients requiring admission to hospital), severe disease (patients requiring additional respiratory support including invasive and non-invasive ventilation). (B) LOS in hypocalcaemic (corrected calcium $<2.2 \mathrm{mmol} / \mathrm{L}$ ) and normocalcaemic $(\geq 2.2$ $\mathrm{mmol} / \mathrm{L})$ patients with COVID-19. Plots show median \pm IQR. ${ }^{* *} \mathrm{P}<0.01 ;{ }^{* * *} \mathrm{p}<0.001 ;{ }^{* * *} \mathrm{p}<0.0001$.

on maximum likelihood fit of the predictive model to the data (table 3). In the final model, variables with the highest ORs (all $\geq 2.00$ ) for predicting a higher level of care were chest radiographic zones, hypocalcaemia, S:F ratio and CRP.

\section{Normalisation of serum calcium level in survivors of severe COVID-19}

To assess trends in calcium level over the course of COVID-19, we identified two groups for analysis: survivors $(\mathrm{n}=74 ; 56 \%$ male; median age 76 , IQR $60-80)$ and nonsurvivors ( $\mathrm{n}=60$; $61 \%$ male; median age 79, IQR 62-83). Both groups shared a similar level of baseline hypocalcaemia $(2.12 \mathrm{mmol} / \mathrm{L}$ vs $2.13 \mathrm{mmol} / \mathrm{L}$, respectively), median length of hospital stay (11 vs 10 days) and avoidance of ICU. Survivors and non-survivors remained hypocalcaemic until days 4-6, though there was a significant difference between the two groups $(2.18 \mathrm{mmol} / \mathrm{L}$ vs 2.13 $\mathrm{mmol} / \mathrm{L}$, respectively, $\mathrm{p}=0.02$ ). By days $7-9$, serum calcium had normalised to $2.25 \mathrm{mmol} / \mathrm{L}$ among survivors whereas it remained below the reference range at $2.13 \mathrm{mmol} / \mathrm{L}$ in non-survivors, similar to admission $(p<0.0001)$. The difference in corrected calcium concentration was even greater 9 days or more after admission. At discharge from hospital, the median calcium concentration was 2.3 $\mathrm{mmol} / \mathrm{L}$ in survivors versus $2.15 \mathrm{mmol} / \mathrm{L}$ in non-survivors (figure 4). None of these patients received calcium supplementation during their hospital admission.

\section{DISCUSSION}

In this retrospective analysis, we found hypocalcaemia to be a common feature of COVID-19, with a frequency and degree of derangement that was greater than in non-COVID-19 CAP and VP. We also observed that low calcium in COVID-19 was associated with measures of abnormal physiology including oxygenation and respiratory rate, radiographic extent of pneumonic involvement and elevated CRP.

Low calcium was specifically linked to severe disease and different levels of hospital care aligned with increasing levels of respiratory support (a surrogate index of severity of COVID-19 pneumonia). Ordinal regression of risk estimates for categorised care levels showed that baseline hypocalcaemia was incrementally associated with an over

Table 2 Hypocalcaemia in patients with COVID-19 at different levels of care

\begin{tabular}{llllll}
\hline & & VH (no suppl $\mathbf{O}_{2}$ ) & Ward (suppl $\mathbf{O}_{\mathbf{2}}$ only) & Ventilatory support (CPAP/IMV) & P value \\
\hline COVID-19 severity & & Ambulatory (mild) & Hospitalised (moderate) & Hospitalised (severe) \\
Calcium & $\geq 2.2 \mathrm{mmol} / \mathrm{L}$ & $\mathrm{n}=57(72.2 \%)$ & $\mathrm{n}=153(46.7 \%)$ & $\mathrm{n}=27(27.8 \%)$ & $\mathrm{n}=70(72.2 \%)$ \\
& $<2.2 \mathrm{mmol} / \mathrm{L}$ & $\mathrm{n}=22(27.8 \%)$ & $\mathrm{n}=175(53.3 \%)$ & $<0.0001$ \\
\hline
\end{tabular}

Number of patients with hypocalcaemia and normocalcaemia and the maximum level of respiratory support/level of care each group required during admission.

CPAP, continuous positive airway pressure; IMV, invasive mechanical ventilation; suppl $\mathrm{O}_{2}$, supplemental oxygen; $\mathrm{VH}$, virtual hospital. 


\begin{tabular}{|c|c|c|c|c|}
\hline Variable & & OR & $95 \% \mathrm{Cl}$ & $P$ value \\
\hline CXR zones & $\begin{array}{l}>4 \\
\text { abnormal }\end{array}$ & 2.48 & 1.53 to 4.01 & $<0.001$ \\
\hline Calcium & $\begin{array}{l}<2.2 \\
\mathrm{mmol} / \mathrm{L}\end{array}$ & 2.33 & 1.50 to 3.61 & $<0.001$ \\
\hline S:F ratio & $<4.38$ & 2.16 & 1.33 to 3.52 & 0.002 \\
\hline CRP & $>50 \mathrm{mg} / \mathrm{L}$ & 2.00 & 1.23 to 3.25 & 0.005 \\
\hline Respiratory rate & $>24 / \min$ & 1.67 & 1.06 to 2.65 & 0.028 \\
\hline Leucocytosis & $>11 \times 10^{9} / \mathrm{L}$ & 1.37 & 0.80 to 2.32 & 0.252 \\
\hline Lymphopenia & $<0.7 \times 10^{9} / L$ & 0.96 & 0.62 to 1.50 & 0.872 \\
\hline
\end{tabular}

Partial proportional odds model that shows the OR of each variable in predicting the need for higher level of care in COVID-19 pneumonia.

CRP, C-reactive protein; CXR, chest X-ray; S:F ratio, oxygen saturation-to-fraction of inspired oxygen ratio.

twofold risk for a higher level of care. Its adjusted OR (2.33) was higher than that for variables that have previously been shown to predict worse COVID-19 outcome, such as hypoxia and tachypnoea. It was also greater than the OR attributed to CRP and nearly as high as that for the extent of radiographic disease.

Unlike some of these parameters, hypocalcaemia has not been included in COVID-19 severity prediction scores. ${ }^{2324}$ However, the distinct association between baseline hypocalcaemia and COVID-19 severity suggests that it could potentially contribute to multivariable stratification of COVID-19 outcome and, importantly, predict

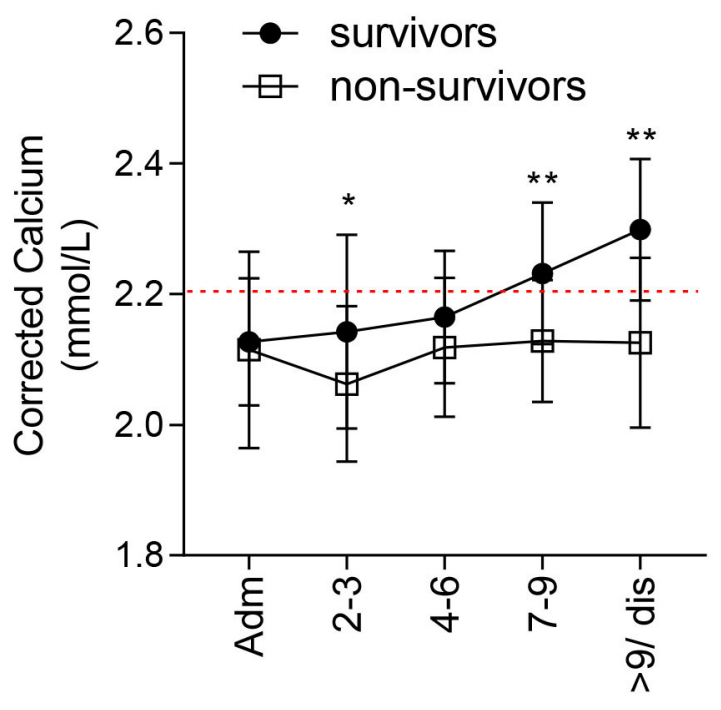

\section{survivors

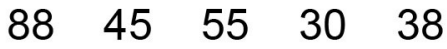 \\ non-survivors $\quad \begin{array}{llllll}91 & 35 & 43 & 33 & 28\end{array}$}

Figure 4 Corrected calcium levels during admission in survivors and non-survivors of COVID-19, hypocalcaemic at presentation. Calcium levels compared at each time point. Plots show median and IQR. ${ }^{*} \mathrm{P}<0.05 ;{ }^{* *} \mathrm{p}<0.01$. the need for additional respiratory support in a select subgroup of young patients without CKD.

Hypocalcaemia has previously been associated with a higher risk of hospitalisation, ${ }^{5}$ ICU admission, ${ }^{10}{ }^{12}$ ventilation and, in some cases, mortality in patients with COVID19. ${ }^{8}$ Our data are consistent with these findings. However, the rate of hypocalcaemia at $53 \%$ in our study was lower than $62 \%-74.4 \%$ reported in other studies. ${ }^{4} 5-10$ This difference may be due to case mix or cohort heterogeneity, specifically the inclusion of patients with mild disease who were managed in a $\mathrm{VH}$ setting in our study.

Low serum calcium is most commonly caused by vitamin D deficiency, insufficient parathyroid hormone (PTH) production and renal dysfunction. In order to reduce the confounding effect of renal failure on hypocalcaemia, these patients were excluded from analysis. There is conflicting evidence on the link between vitamin D deficiency and COVID-19 severity; one retrospective study from Israel reported independent associations between low prepandemic vitamin $\mathrm{D}$ levels and subsequent incidence and severity of COVID- $19,{ }^{25}$ but an analogous study in the UK failed to show such associations. ${ }^{26}$ In a preliminary analysis of 30 patients with mild versus severe COVID-19, we found that whereas calcium levels were significantly lower in severe disease, vitamin D levels were not (online supplemental figure 3). A larger sample size, matched for age and ethnicity (which both impact vitamin D levels), is necessary to further corroborate these preliminary findings.

The role of PTH in COVID-19 is unclear but normal PTH levels have been reported in a limited study of hospitalised patients with this disease. ${ }^{10}$ While it is unlikely that PTH insufficiency is the sole or even primary driver of hypocalcaemia in COVID-19, this area requires further investigation.

Two clinically important coronaviruses, SARS-CoV-1 and Middle East respiratory syndrome-CoV, can use calcium ions to enter host cells, mediated by a fusion peptide derived from the viral spike protein. ${ }^{27}{ }^{28}$ It could be postulated that similar calcium-dependent mechanisms might operate during the pathogenic process involving calcium handling during SARS-CoV-2-mediated infection. In support of this hypothesis, calcium channel blockers including amlodipine have been shown to inhibit postentry replication events of SARS-CoV-2 in vitro. ${ }^{29}$ In one observational study, amlodipine therapy was also associated with a decreased case fatality rate in hospitalised patients with COVID-19. ${ }^{29}$ Other mechanisms of calcium-mediated inflammation and tissue injury may involve the activation of the viral NLRP3 inflammasome leading to interleukin-1 beta overproduction and downstream activation and propagation of tissue inflammatory cascades. ${ }^{1730-32}$

Hypocalcaemia is common in critically ill patients, with a reported prevalence of up to $88 \%$ of all patients admitted to intensive care ${ }^{3334}$ In our study, baseline hypocalcaemia was frequently evident in patients with COVID-19 even among those who were not ultimately admitted to the 
ICU. Patients with COVID-19 also had comparable baseline illness characteristics as $\mathrm{CAP}$, such as respiratory rate, S:F ratio, prevalence of elevated CRP and frequency of lymphopenia. However, the frequency of hypocalcaemia was significantly higher and the median concentration of serum calcium was lower in those patients with COVID-19 compared with those with CAP. This finding suggests the possibility of hypocalcaemia being pathophysiologically more pertinent in COVID-19. In line with this, a lower serum calcium level within the COVID-19 subgroup was clearly associated with worse respiratory illness and a need for greater respiratory support.

Our study was limited by its retrospective design and resultant occurrence of missing data ( $<15 \%$ for COVID-19 and CAP subgroups), with the fullest data available for COVID-19 and the least for patients with VP. The modest sample size of our COVID-19 cohort was dependent on the incident case load during the first wave of the pandemic, and a small sample size of patients with CAP and VP. The data on vitamin D and PTH measurements were insufficient as these parameters were not routinely measured in the management of COVID-19 or the other pneumonias. In addition, the measurement of ionised calcium (the unbound calcium available to cells) would be more accurate and physiologically relevant than measuring the total body calcium corrected for albumin. ${ }^{35}$ However, in the absence of ionised calcium measurements, corrected calcium was felt to be a reasonable alternative that more accurately reflected calcium stores compared with calcium that was not adjusted for protein binding.

Our data show that hypocalcaemia is clinically important during both the acute presentation of COVID-19 as well as its subsequent evolution to more severe respiratory failure. Further studies are required to help bridge the biological understanding of hypocalcaemia and its pathophysiological significance to this devastating disease. If calcium is ultimately shown to be critical to the entry and replication of SARS-CoV-2 in host cells, unravelling how this mechanism could be therapeutically targeted deserves more intensive examination.

\section{Author affiliations}

${ }^{1}$ Respiratory Medicine, West Hertfordshire Hospitals NHS Trust, Watford, UK ${ }^{2}$ Interstitial Lung Disease Unit, Royal Brompton and Harefield NHS Foundation Trust, London, UK

${ }^{3}$ National Heart and Lung Institute, Imperial College London, London, UK

${ }^{4}$ Respiratory Medicine, St George's Hospital, London, UK

Contributors Guarantor: MM. Study concept and design: MM, AB, RV. Acquisition of data: MM, HG, SC, MP, RS, TV. Analysis and interpretation of data: MM, FC, AD, RV. Drafting of the manuscript: MM, FC, AD, RV. Critical revision of manuscript: all authors.

Funding The authors have not declared a specific grant for this research from any funding agency in the public, commercial or not-for-profit sectors.

Competing interests None declared.

Patient consent for publication Not required.

Ethics approval Ethical approval was granted for the prospective recruitment of human data on adult patients with positive SARS-CoV-2 nucleic acid testing by real-time reverse transcription PCR (rRT-PCR) at Watford General Hospital, West Hertfordshire NHS Trust. Ethical Review Board: HRA (NHS HRA: 20/HRA/2344).
Provenance and peer review Not commissioned; externally peer reviewed.

Data availability statement Data are available upon reasonable request.

Supplemental material This content has been supplied by the author(s). It has not been vetted by BMJ Publishing Group Limited (BMJ) and may not have been peer-reviewed. Any opinions or recommendations discussed are solely those of the author(s) and are not endorsed by BMJ. BMJ disclaims all liability and responsibility arising from any reliance placed on the content. Where the content includes any translated material, BMJ does not warrant the accuracy and reliability of the translations (including but not limited to local regulations, clinical guidelines, terminology, drug names and drug dosages), and is not responsible for any error and/or omissions arising from translation and adaptation or otherwise.

Open access This is an open access article distributed in accordance with the Creative Commons Attribution Non Commercial (CC BY-NC 4.0) license, which permits others to distribute, remix, adapt, build upon this work non-commercially, and license their derivative works on different terms, provided the original work is properly cited, appropriate credit is given, any changes made indicated, and the use is non-commercial. See: http://creativecommons.org/licenses/by-nc/4.0/.

\section{ORCID iDs}

Meera Mehta http://orcid.org/0000-0001-7551-5357

Hakim Ghani http://orcid.org/0000-0002-0264-3355

\section{REFERENCES}

1 Carr E, Bendayan R, Bean D, et al. Evaluation and improvement of the National early warning score (NEWS2) for COVID-19: a multihospital study. BMC Med 2021;19:23.

2 Gupta RK, Harrison EM, Ho A, et al. Development and validation of the ISARIC 4C deterioration model for adults hospitalised with COVID-19: a prospective cohort study. Lancet Respir Med 2021;9:349-59.

3 Knight SR, Ho A, Pius R, et al. Risk stratification of patients admitted to hospital with covid-19 using the ISARIC WHO clinical characterisation protocol: development and validation of the $4 \mathrm{C}$ mortality score. BMJ 2020;370:m3339.

4 Cappellini F, Brivio R, Casati M, et al. Low levels of total and ionized calcium in blood of COVID-19 patients. Clin Chem Lab Med 2020;58:e171-3.

5 Di Filippo L, Formenti AM, Rovere-Querini P, et al. Hypocalcemia is highly prevalent and predicts hospitalization in patients with COVID-19. Endocrine 2020;68:475-8.

6 Di Filippo L, Formenti AM, Rovere-Querini P, et al. Hypocalcemia is highly prevalent and predicts hospitalization in patients with COVID-19. Endocrine 2020;68:475-8.

7 Lippi G, South AM, Henry BM. Electrolyte imbalances in patients with severe coronavirus disease 2019 (COVID-19). Ann Clin Biochem 2020;57:262-5.

8 Liu J, Han P, Wu J, et al. Prevalence and predictive value of hypocalcemia in severe COVID-19 patients. J Infect Public Health 2020;13:1224-8.

$9 \mathrm{Wu}$ Y, Hou B, Liu J, et al. Risk factors associated with long-term hospitalization in patients with COVID-19: a Single-Centered, retrospective study. Front Med 2020;7:315.

10 Sun J-K, Zhang W-H, Zou L, et al. Serum calcium as a biomarker of clinical severity and prognosis in patients with coronavirus disease 2019. Aging 2020;12:11287-95.

11 Tezcan ME, Dogan Gokce G, Sen N, et al. Baseline electrolyte abnormalities would be related to poor prognosis in hospitalized coronavirus disease 2019 patients. New Microbes New Infect 2020;37:100753.

12 Torres B, Alcubilla P, González-Cordón A, et al. Impact of low serum calcium at hospital admission on SARS-CoV-2 infection outcome. Int $J$ Infect Dis 2021;104:164-8.

13 Clapham DE. Calcium signaling. Cell 2007;131:1047-58.

14 Bai D, Fang L, Xia S, et al. Porcine deltacoronavirus (PDCoV) modulates calcium influx to favor viral replication. Virology 2020;539:38-48.

15 Doñate-Macián P, Jungfleisch J, Pérez-Vilaró G, et al. The TRPV4 channel links calcium influx to DDX3X activity and viral infectivity. Nat Commun 2018;9:2307.

16 Ueda M, Daidoji T, Du A, et al. Highly pathogenic H5N1 avian influenza virus induces extracellular $\mathrm{Ca} 2+$ influx, leading to apoptosis in avian cells. J Virol 2010;84:3068-78.

17 Nieto-Torres JL, Verdiá-Báguena C, Jimenez-Guardeño JM, et al. Severe acute respiratory syndrome coronavirus $\mathrm{E}$ protein transports 
calcium ions and activates the NLRP3 inflammasome. Virology 2015;485:330-9.

18 Sarkar M, Saha S. Structural insight into the role of novel SARSCoV-2 E protein: a potential target for vaccine development and other therapeutic strategies. PLoS One 2020;15:e0237300.

19 Chua F, Vancheeswaran R, Draper A, et al. Early prognostication of COVID-19 to guide hospitalisation versus outpatient monitoring using a point-of-test risk prediction score. Thorax 2021;76:696-703.

20 Shen Lim W, Baudouin S, George R. Guidelines for the management of community Aquired pneumonia in adults, update 2009. British Thoracic Society 2009 https://www.brit-thoracic.org.uk/qualityimprovement/guidelines/pneumonia-adults/

21 The Guideline Development Group, National Collaborating Centre and NICE project team. Chronic kidney disease in adults: assessment and management, 2014.

22 WHO Working Group on the Clinical Characterisation and Management of COVID-19 infection. A minimal common outcome measure set for COVID-19 clinical research. Lancet Infect Dis 2020;20:e192-7.

23 Peterson B, Harrell FE. Partial proportional odds models for ordinal response variables. Appl Stat 1990;39:205-17.

24 Huang H, Cai S, Li Y, et al. Prognostic factors for COVID-19 pneumonia progression to severe symptoms based on earlier clinical features: a retrospective analysis. Front Med 2020;7:557453.

25 Merzon E, Tworowski D, Gorohovski A, et al. Low plasma $25(\mathrm{OH})$ vitamin $\mathrm{D}$ level is associated with increased risk of COVID-19 infection: an Israeli population-based study. Febs $J$ 2020;287:3693-702.
26 Raisi-Estabragh Z, McCracken C, Bethell MS, et al. Greater risk of severe COVID-19 in Black, Asian and Minority Ethnic populations is not explained by cardiometabolic, socioeconomic or behavioural factors, or by $25(\mathrm{OH})$-vitamin D status: study of 1326 cases from the UK Biobank. J Public Health 2020;42:451-60.

27 Millet JK, Whittaker GR. Physiological and molecular triggers for SARS-CoV membrane fusion and entry into host cells. Virology 2018;517:3-8.

28 Straus MR, Tang T, Lai AL. Ca 2+ ions promote fusion of middle East respiratory syndrome coronavirus with host cells and increase infectivity. Gallagher T, editor. J Virol 2020;94:13.

29 Zhang L-K, Sun Y, Zeng H, et al. Calcium channel blocker amlodipine besylate therapy is associated with reduced case fatality rate of COVID-19 patients with hypertension. Cell Discov 2020;6:96.

30 Cron RQ, Caricchio R, Chatham WW. Calming the cytokine storm in COVID-19. Nat Med 2021;27:1674-5.

31 Huet T, Beaussier $\mathrm{H}$, Voisin O, et al. Anakinra for severe forms of COVID-19: a cohort study. Lancet Rheumatol 2020;2:e393-400.

32 Murakami T, Ockinger J, Yu J, et al. Critical role for calcium mobilization in activation of the NLRP3 inflammasome. Proc Nat/ Acad Sci U S A 2012;109:11282-7.

33 Zaloga GP. Hypocalcemia in critically ill patients. Crit Care Med 1992;20:251-62.

34 Zivin JR, Gooley T, Zager RA, et al. Hypocalcemia: a pervasive metabolic abnormality in the critically ill. Am J Kidney Dis 2001;37:689-98.

35 Kelly A, Levine MA. Hypocalcemia in the critically ill patient. $J$ Intensive Care Med 2013;28:166-77. 